\title{
Coloração de cortes cozidos de frangos alimentados com urucum
}

\author{
Coloration of cooked broiler cuts fed with annatto
Marcia Nalesso Costa HARDER ${ }^{1 \star}$, Fernanda Papa SPADA², Vicente José Maria SAVINO², Antonio Augusto Domingos COELHO ${ }^{2}$, Edival CORRER ${ }^{2}$, Edmilson MARTINS²

\begin{abstract}
Resumo
Para atender às necessidades do mercado consumidor e, assim, agregar valor ao seu produto, a indústria avícola tem procurado formas de se ajustar a esse padrão. Sendo o urucum um excelente pigmentante, este trabalho teve como objetivo avaliar o comportamento do corante na carne de frango cozida. Cem animais foram divididos em quatro grupos e tratados com $0 ; 1 ; 2 ;$ e $3 \%$ de urucum incluso na ração. Para avaliação da coloração dos cortes, foi utilizado o sistema Hunter Lab. Para o parâmetro L, os cortes de peito foram inversamente proporcionais aos cortes de coxa, diminuindo, conforme aumento da porcentagem de urucum para peito, e aumentando, para coxa. Para o parâmetro Croma, os cortes apresentaram comportamento semelhante, aumentando, conforme aumentou a porcentagem de urucum. Os demais parâmetros (a, b e Hue-Angle) não tiveram diferenças significativas. Portanto, a utilização de urucum, com a intenção de aumentar a pigmentação da carne frangos, aumenta conforme aumenta a porcentagem de urucum na ração dos animais.
\end{abstract}

Palavras-chave: Bixa orellana L.; sistema Hunter Lab; coloração de carnes; carne de frango.

\begin{abstract}
The poultry industry has been making an effort to satisfy the needs of the consumers and to add value to their products. Since Annatto is considered an excellent color additive, the aim of this study is to evaluate its behavior in the cooked broiler meat. A hundred animals were divided into four groups and treated with $0 ; 1 ; 2$, and $3 \%$ of annatto in the feed. For the evaluation of the coloration of the cuts, the Hunter Lab system was used. For the parameter L, the breast cuts were inversely proportional to legs cuts, decreasing with the increase of the annatto percentage for the breast cuts and increasing for the leg cuts. For the parameter Chroma, the cuts presented similar behavior, increasing with the increase of the annatto percentage. The other parameters ( $a, b$, and Hue-Angle) did not present significant differences. Therefore, the use of annatto to increase pigmentation in broiler meats increases with the increase of the annatto percentage in the feed of the animals.
\end{abstract}

Keywords: Bixa orellana L.; Hunter Lab system; meat coloration; broiler meat.

\section{Introdução}

O comércio da carne de frango cresce a cada ano na escala mundial, visto que a carne de frango é fonte barata de proteína de origem animal, entretanto existe o crescimento significativo de sistemas alternativos voltados a exigências específicas de determinados segmentos de mercado.

O frango é a única espécie conhecida que possui músculos com cores extremas: o peito possui cor rosa pálida, enquanto que a porção da coxa e sobrecoxa possuem coloração vermelha intensa, in natura. A pigmentação da carne de frango é fortemente influenciada pela presença de carotenoides na alimentação, conhecidos como xantofilas, que contribuem para a pigmentação (PÉREZ-VENDRELL et al., 2001).

Ang e Huang (1994) estudaram o efeito da temperatura atingida no centro de empadas, feitas a partir da coxa de frango, na faixa de 60 a $85^{\circ} \mathrm{C}$, sobre a cor (medida no sistema Hunter Lab) de carne cozida em grelha. Eles verificaram que, quando se aumenta a temperatura, a luminosidade (L) e o amarelo versus azul (b) aumentam; enquanto que o vermelho versus verde (a) diminui.
Neste contexto, segundo Englert (1998) os consumidores dão preferência a frangos com pele bem pigmentada, Allen et al. (1998), Barbut (2001), Qiao et al., (2002) afirmam ainda que a coloração da carne de frango in natura é importante, uma vez que os consumidores associam a cor dos produtos com as características de frescor e de boa qualidade. Assim, esta característica interfere diretamente na decisão de compra do consumidor.

Harder et al. (2007) relatam que o urucum é amplamente utilizado como pigmentante para a indústria avícola.

A importância do urucum se deve principalmente às limitações no uso de corantes artificiais em alimentos, levando a indústria alimentícia a optar pela exploração de corantes naturais (HARDER et al., 2007), em especial os extraídos da semente de urucum: bixina e norbixina (TONAMI, 1995; FRANCO et al., 2002; HARDER et al., 2007; FRANCO et al., 2008).

A incorporação de urucum in natura e de seus resíduos industriais na alimentação de animais ruminantes e não

Recebido para publicação em 8/8/2008

Aceito para publicação em 16/5/2009 (003708)

${ }^{1}$ Centro de Energia Nuclear na Agricultura, Irradiação de Alimentos e Radioentomologia, Universidade de São Paulo - USP, CEP 13400-970, Piracicaba - SP, Brasil,

E-mail: mnharder@terra.com.br

${ }^{2}$ Genética, Escola Superior de Agricultura "Luiz de Queiroz", Universidade de São paulo - USP, CEP 13418-900, Piracicaba-SP, Brasil

${ }^{*}$ A quem a correspondência deve ser enviada 
ruminantes vem sendo estudada desde 1955, sendo que estudos mais recentes de Tonami (1995), Utiyama (2001) e Harder (2005) incorporaram urucum respectivamente na alimentação de bovinos, suínos e poedeiras, entretanto somente Harder (2005) associou o corante urucum com a coloração (gema dos ovos produzidos pelas poedeiras), demonstrando que o urucum atua de forma eficiente na incorporação de carotenoides à gema, fator esse que, segundo Rodrigues e Salay (2001), influencia diretamente na qualidade do produto perante o consumidor.

Seguindo esta tendência, este experimento teve como objetivo determinar como a incorporação de urucum na dieta de frangos de corte influencia a coloração da carne de peito e coxa, com relação à estabilidade da coloração após cozimento.

\section{Material e métodos}

O experimento foi realizado no Departamento de Genética da ESALQ - USP, no Setor de Aves, no período de outubro a dezembro de 2007.

Foram utilizadas 100 aves da linhagem (Ross-Agroceres), distribuídas em 4 tratamentos, sendo um tratamento controle (T0), alimentado com ração comercial, e os demais tratamentos (T1, T2 e T3) foram alimentados com a mesma ração comercial acrescida respectivamente de 1; 2; e 3\% de urucum moído.

A ração foi preparada em dois lotes distintos, para evitar envelhecimento da ração e problemas quanto à oxidação.

O primeiro lote de ração (inicial) foi preparado no início do experimento, e o segundo lote de ração (final), preparado no dia anterior a sua utilização.

A moagem do urucum foi realizada em moinho convencional de fábrica de ração, sendo utilizada a peneira de número dois. Com a padronização da moagem do urucum, eliminaram-se possíveis problemas quanto à oxidação do urucum.

Cada mistura ficou durante cinco minutos em misturador de formato de "Y" para homogeneização da ração.

As aves foram pesadas no momento do alojamento, mesmo dia do nascimento ( $1^{\circ}$ dia experimental), na troca da ração inicial pela de engorda (que ocorreu no $22^{\circ}$ dia de idade das aves) e no dia anterior ao abate, que foi realizado no $41^{\circ}$ dia experimental. Água e ração foram fornecidas à vontade durante todo o experimento, exceto 12 horas antes do abate, para esvaziamento do trato gastrintestinal, para se evitar contaminação da carcaça.

Aos 41 dias de idade das aves, foi realizado o abate. As aves foram imersas em água, à temperatura de $60^{\circ} \mathrm{C}$, para facilitar a retirada das penas com a depenadeira (ROQUE, 1996), posteriormente, foi feita a pesagem da ave, bem como a pesagem individual das partes utilizadas para a realização da análise de cor (peito e coxas) e para a análise do rendimento de peito e coxa.

Foi retirada a porção inferior do músculo Pectoralis major da carne de vinte peitos, por tratamento, bem como a porção inferior da coxa. Os cortes foram cozidos em duas etapas distintas, uma para as porções de peito e outra para as porções da coxa.
Estas porções foram então alocadas em Becker de $1 \mathrm{~L}$, sendo completado o volume com água até a marca de $600 \mathrm{~mL}$. Os recipientes foram então envolvidos com papel alumínio e levados para a autoclave, até se alcançar 120 atm de pressão, deixando-os por 3 minutos nesta condição. Posteriormente desligou-se o equipamento e aguardou-se o resfriamento do produto. As partes foram então separadas do bloco de cozimento e lavadas, para a retirada de uma película gelatinosa formada durante o processo de cozimento, e depositadas em bandejas individuais para secagem e leitura de cor (FANTINI et al., 2008).

Com o auxílio do equipamento Minolta Chroma Meter, Modelo CR-400 (Tóquio, Japão), foi possível mensurar os parâmetros colorimétricos de L (luminosidade), a (intensidade de vermelho/verde) e b (intensidade de amarelo/azul), sistema Hunter Lab, com fonte iluminante D65, calibrado em porcelana branca com padrão de $\mathrm{Y}=93,7 ; \mathrm{x}=0,3160$ e y $=0,3323$.

O Croma é a relação entre os valores de a e b, em que se obtém o valor da cor real da amostra analisada. Hue-Angle é o ângulo formado entre a e b, indicando a saturação da cor da amostra (HARDER, 2005).

\section{Resultado e discussão}

De acordo com a Tabela 1, temos que: para a coloração dos peitos cozidos das 20 aves analisadas, não houve diferença significativa para os parâmetros a, b e Croma. Entretanto a luminosidade (L) apresentou diferença estatística, quando comparada às amostras T2 e T3.

Com relação ao parâmetro Hue-Angle, também houve diferença estatística para a amostra $\mathrm{T} 3$ com relação às amostras T1 e T2.

Observa-se que houve uma diminuição da intensidade da luminosidade conforme a administração do urucum, assim como também, inversamente proporcional, houve um aumento dos valores de Croma.

O Hue-Angle (ângulo de saturação da cor) também teve uma tendência a aumentar conforme o aumento da administração de urucum. Houve, porém, uma queda na quantidade máxima de urucum.

$\mathrm{Na}$ análise das amostras das vinte coxas cozidas, temos que os parâmetros L, a e Hue-Angle não apresentaram diferença significativa. Para as variáveis b e Croma, existe em ambos os casos diferença estatisticamente significativa entre as amostras T0 e T3, sendo que, como era esperado, a amostra T3 apresentou maior intensidade de coloração, conforme demonstra a Tabela 2.

Com relação a L, a carne da coxa apresentou um comportamento contrário ao da carne de peito, aumentando conforme a administração de urucum, porém apresentou-se da mesma forma, com relação ao Croma, aumentando conforme o aumento de urucum.

O ângulo de saturação das carnes de coxas não sofreu alteração, comportando-se também diferente da carne do peito. 
Harder et al.

Tabela 1. Valores médios e desvio padrão dos parâmetros L, a, b e Croma para peito cozido.

\begin{tabular}{cccccc}
\hline Tratamento & L & a & b & Croma & Hue-Angle \\
\hline T0 & $74,08 \pm 2,656^{\text {1ab2 }}$ & $3,71 \pm 0,900^{\mathrm{a}}$ & $16,39 \pm 2,100^{\mathrm{a}}$ & $16,83 \pm 2,078^{\mathrm{a}}$ & $1,35 \pm 0,056^{\mathrm{ab}}$ \\
T1 & $73,49 \pm 3,892^{\mathrm{ab}}$ & $3,60 \pm 1,135^{\mathrm{a}}$ & $16,47 \pm 1,451^{\mathrm{a}}$ & $16,89 \pm 1,434^{\mathrm{a}}$ & $1,36 \pm 0,068^{\mathrm{a}}$ \\
T2 & $75,16 \pm 4,762^{\mathrm{a}}$ & $3,27 \pm 0,744^{\mathrm{a}}$ & $17,11 \pm 1,248^{\mathrm{a}}$ & $17,43 \pm 1,252^{\mathrm{a}}$ & $1,38 \pm 0,043^{\mathrm{a}}$ \\
T3 & $70,72 \pm 5,664^{\mathrm{b}}$ & $3,99 \pm 0,970^{\mathrm{a}}$ & $16,52 \pm 1,865^{\mathrm{a}}$ & $17,01 \pm 1,921^{\mathrm{a}}$ & $1,33 \pm 0,050^{\mathrm{b}}$ \\
\hline
\end{tabular}

${ }^{1}$ Média \pm desvio padrão; ${ }^{2}$ letras minúsculas diferentes na vertical diferem entre si com nível de significância de $5 \%$.

Tabela 2. Valores médios e desvio padrão dos parâmetros L, a, b e Croma para coxa cozida.

\begin{tabular}{cccccc}
\hline Tratamento & L & a & b & Croma & Hue-Angle \\
\hline T0 & $69,27 \pm 3,681^{1 \mathrm{a} 2}$ & $4,12 \pm 0,959^{\mathrm{a}}$ & $14,84 \pm 0,959^{\mathrm{b}}$ & $15,42 \pm 1,667^{\mathrm{b}}$ & $1,30 \pm 0,064^{\mathrm{a}}$ \\
T1 & $68,48 \pm 4,388^{\mathrm{a}}$ & $4,49 \pm 1,132^{\mathrm{a}}$ & $16,50 \pm 1,132^{\mathrm{ab}}$ & $17,14 \pm 2,565^{\mathrm{ab}}$ & $1,30 \pm 0,074^{\mathrm{a}}$ \\
T2 & $68,02 \pm 4,319^{\mathrm{a}}$ & $4,32 \pm 1,181^{\mathrm{a}}$ & $16,46 \pm 1,181^{\mathrm{ab}}$ & $17,14 \pm 2,192^{\mathrm{ab}}$ & $1,31 \pm 0,074^{\mathrm{a}}$ \\
T3 & $68,56 \pm 3,846^{\mathrm{a}}$ & $4,66 \pm 1,005^{\mathrm{a}}$ & $16,78 \pm 1,005^{\mathrm{a}}$ & $17,43 \pm 2,217^{\mathrm{a}}$ & $1,30 \pm 0,055^{\mathrm{a}}$ \\
\hline
\end{tabular}

${ }^{1}$ Média \pm desvio padrão; 2 letras minúsculas diferentes na vertical diferem entre si com nível de significância de $5 \%$.

Os resultados obtidos discordam, somente no parâmetro L, com Ang e Huang (1994), que avaliaram a cor da carne de frango cozida no interior de empadas, e concordam nos demais atributos.

Estes autores obtiveram valores para $\mathrm{L}$ de aproximadamente 67 , ficando abaixo dos valores encontrados neste trabalho, que se apresentaram ao redor de 68 a 75.

Já, para a e b, os valores encontrados foram próximos, ligeiramente inferiores. O quantitativo apresentado pelos autores e por este trabalho foi: para a, os valores foram de aproximadamente 4; e para b, os valores foram ao redor de 17.

Racanicci et al. (2008) encontraram valores inferiores. Para L, apresentaram valores ao redor de 47, para sobrecoxas; para a, apresentaram valores superiores; e para b, valores inferiores aos encontrados.

\section{Conclusões}

Pode-se concluir que o aumento da coloração da carne de frango foi verificado mesmo após o cozimento da carne, ou seja, não se perdeu nesta operação unitária. Já que a utilização de urucum na alimentação de frangos de corte apresentou tendência a aumentar a coloração da carne, fato este principalmente evidenciado com o acréscimo de $3 \%$ do aditivo na alimentação animal, o urucum pode ser utilizado como agente pigmentante para melhorar a coloração dos cortes de carne de frangos.

\section{Referência bibliográfica}

ALLEN, C. D. et al. The relationship of broiler breast color to meat quality and shelf-life. Poultry Science, n. 77, v. 2, p. 361-366, 1998.

ANG, C. Y. W.; HUANG, Y. W. Color changes of chicken leg patties due to end-point temperature, packaging and refrigerated storage. Journal of Food Science, Chicago, v. 59, n. 1, p. 26-29, 1994.

BARBUT, S. Effect of illumination source on the appearance of fresh meat cuts. Meat Science, v. 59, n. 1, p. 187-191, 2001.
ENGLERT, S. I. Avicultura: tudo sobre raças, manejo e alimentação. 7. ed. Guaíba: Livraria e Editora Agropecuária, 1998. 238 p.

FANTINI, A. P. et al. Disponibilidade de ferro em misturas de alimentos com adição de alimentos com alto teor de vitamina C e de cisteína. Ciência e Tecnologia de Alimentos, v. 28, n. 2, p. 435-439, 2008.

FRANCO, C. F. O. et al. Urucum: sistemas de produção para o Brasil. João Pessoa: EMEPA, 2008. 112 p.

FRANCO, C. F. O. et al. Uurucum: agronegócio de corantes naturais. João Pessoa: SAIA, 2002. $120 \mathrm{p}$.

HARDER, M. N. C. Efeito do urucum (Bixa orellana) na alteração de características de ovos de galinhas poedeiras. 2005. 74 p. Dissertação (Mestrado) - Universidade de São Paulo, Piracicaba, 2005.

HARDER, M. N. C. et al. Cholesterol and iron availability in yolk of laying hens feed with annatto (Bixa orellana). Animal, v. 1, n. 1, p. 477-482, 2007.

PÉREZ-VENDRELL, A. M. et al. Influence of source and ratio of xantophyll pigments on broiler chicken pigmentation and performance. Poultry Science, v. 80, n. 2, p. 320-326, 2001.

QIAO, M. et al. The relationship between raw broiler breast meat color and composition. Poultry Science, v. 81, n. 2, p. 422-427, 2002.

RACANICCI, A. M. C. et al. Efeito do uso de óleo de víceras de aves oxidado na ração de frangos de corte sobre o desempenho, a composição da carcaça e a estabilidade oxidativa da carne da sobrecoxa. Revista Brasileira de Zootecnia, v. 37, n. 3, p. 443-449, 2008.

RODRIGUES, K. R. M.; SALAY, E. Atitudes de granjeiros, atacadistas, varejistas e consumidores em relação à qualidade sanitária do ovo de galinha in natura. Revista de Nutrição, v. 14, n. 3, p. 185-193, 2001.

ROQUE, V. F. Aproveitamento de resíduos de carne de frango: uma análise exploratória. 1996. Dissertação (Mestrado) - Universidade Federal de Santa Catarina, Florianópolis, 1996.

TONAMI, F. Estudo do valor nutritivo da semente de urucum (Bixa orellana L.) e seu efeito sobre o desempenho de bovinos de corte. Jaboticabal: FCAV/UNESP, 1995. 11p. Parecer técnico.

UTIYAMA, C. E. Utilização de resíduo de sementes processadas de urucum (Bixa orellana L.) na alimentação de suínos em crescimento. 2001. 43 p. Dissertação (Mestrado) - Universidade de São Paulo, Piracicaba, 2001. 